\title{
A Note on Japanese Names
}

Throughout this book Japanese names are given in the traditional order, with the family name (e.g., Kawabata) followed by the personal name (Yasunari). After a well-known author's death, however, he is often referred to by his personal name alone (e.g., Ōgai for Mori Ōgai, and Saikaku for Ihara Saikaku). 


\section{THE MOON IN THE WATER}


